\title{
Heterologous Prime-Boost Vaccination Enhances TsPmy's Protective Immunity against Trichinella spiralis Infection in a Murine Model
}

\author{
Lei Wang ${ }^{1,2}$, Ximeng Sun'2, Jingjing Huang ${ }^{2}$, Bin Zhan ${ }^{3}$ and Xinping Zhu' ${ }^{2,4 *}$ \\ ' Beijing Tropical Medicine Research Institute, Beijing Friendship Hospital, Capital Medical University, Beijing, China, \\ ${ }^{2}$ Department of Medical Microbiology and Parasitology, School of Basic Medical Sciences, Capital Medical University, \\ Beijing, China, ${ }^{3}$ Department of Pediatrics, National School of Tropical Medicine, Baylor College of Medicine, Houston, TX, \\ United States, ${ }^{4}$ Research Centre of Microbiome, Capital Medical University, Beijing, China
}

OPEN ACCESS

Edited by:

Wei Hu,

Fudan University, China

Reviewed by:

Zhong Quan Wang,

Zhengzhou University, China

Xing-Quan Zhu,

Lanzhou Institute of Veterinary

Research (CAAS), China

${ }^{*}$ Correspondence:

Xinping Zhu

zhuxping@ccmu.edu.cn

Specialty section:

This article was submitted to

Infectious Diseases,

a section of the journal

Frontiers in Microbiology

Received: 10 May 2017

Accepted: 10 July 2017

Published: 21 July 2017

Citation:

Wang L, Sun X, Huang J, Zhan B and Zhu $X$ (2017) Heterologous Prime-Boost Vaccination Enhances TSPmy's Protective Immunity against Trichinella spiralis Infection in a Murine Model. Front. Microbiol. 8:1394. doi: 10.3389/fmicb.2017.01394
TsPmy is a paramyosin expressed by parasitic Trichinella spiralis and confers a protective immunity when its recombinant protein or DNA was used as an immunogen. To improve its immunogenicity and vaccine efficacy, we conducted a heterologous prime-boost strategy by orally delivering one dose of TsPmy DNA carried by attenuated Salmonella typhimurium (SL7207), followed by two doses of recombinant TsPmy intramuscularly. This strategy effectively induced intestinal mucosal slgA response and an enhanced and balanced Th1/Th2 immune responses that improve protection against $T$. spiralis larval challenge, with $55.4 \%$ muscle larvae reduction and $41.8 \%$ adult worm reduction compared to PBS control. The muscle larvae reduction induced by heterologous primeboost regimen was significant higher than that induced by the homologous DNA or protein prime-boost regimens, which could act as a practical prophylactic approach to prevent $T$. spiralis infection.

Keywords: Trichinella spiralis, vaccine, prime-boost, mucosal immunity, Salmonella typhimurium

\section{INTRODUCTION}

Trichinellosis remains endemic in 66 countries with estimated 11 million people infected with Trichinella spiralis around the world (Dupouy-Camet, 2000). Only in China, total 32 outbreaks of human trichinellosis with 2,215 cases and 15 deaths have been reported during 2000 to 2009 (Wang et al., 2006; Cui et al., 2011). T. spiralis infects not only humans but also a wide range of domestic and wild animals that becomes major source of human infection through eating undercooked meat contaminated with infected larvae. The infected domestic animals such as porcine as major source for human infection make it difficult to control endemic of trichinellosis. There is a need to develop vaccine as an alternative approach to control the infection.

Many efforts have been made to develop vaccines against trichinellosis during the past decades, including vaccines based on worm crude larval extracts, recombinant proteins, DNA or multipleepitope peptide which induced certain extent of protective immunity in animal models (Gu et al., 2008; Wang et al., 2009; Wei et al., 2011). However, these traditional vaccines and immunization regimen present challenges with insufficient protective effect against $T$. spiralis infection. Except 
for selecting the proper vaccine candidate which induces the best protective immunity, it is also very important to optimize the immunization regimen such as immunization schedule, route of administration, vaccine dose and delivery systems as well as adjuvants in order to achieve the best protective efficacy (Kardani et al., 2016).

Trichinella spiralis is an intestinal nematode that develops to adult worm in small intestine in which male and female worms mate and female worms lay newborn larvae. The later penetrate the intestine and migrate to muscle tissue where they form cysts. Thus, intestinal mucosa is the first crucial barrier against Trichinella infection and larva migration. The mucosal immune response in the gut is likely to be important in protecting the host against $T$. spiralis infection (Picherot et al., 2007). In our previous study, attenuated Salmonella typhimurium (SL7207) was used as delivery system to orally deliver a DNA vaccine of TsPmy (Wang et al., 2016), a leading vaccine candidate for trichinellosis (Yang et al., 2008, 2010; Wei et al., 2011; Gu et al., 2013). Mice orally inoculated with TsPmy/Salmonella DNA vaccine displayed strong intestinal mucosal and systemic immune responses which resulted in $44.8 \%$ reduction in adult worm and $46.6 \%$ reduction in muscle larvae against T. spiralis larval challenge (Wang et al., 2016).

Heterologous prime-boost immunization regimen, primed by DNA vaccine and boosted by recombinant protein, has be proven to induce stronger cellular and humoral immunity (Jackson et al., 2014; Kardani et al., 2016) and the better protection against some infectious diseases such as Leishmania infantum (Shahbazi et al., 2015), Toxoplasma gondii (Han et al., 2017), Plasmodium yoelii (Cabrera-Mora et al., 2016), and Schistosoma japonicum (Dai et al., 2017). In present study we used Salmonelladelivered TsPmy DNA as prime immunization followed by two boost immunizations with expressed recombinant Ts Pmy protein (rTsPmy) in order to enhance TsPmy's immunogenicity and protective efficacy against $T$. spiralis infection in a murine model.

\section{MATERIALS AND METHODS}

\section{Ethics Statement}

Female BALB/c mice, 6-8 week-old and free of specific pathogens, were obtained from Laboratory Animal Services Center of Capital Medical University (Beijing, China). All mice were maintained under specific pathogen-free conditions at an appropriate temperature and humidity. Experimental procedures were consistent in strict with the NIH Guide for the Care and Use of Laboratory Animals, that were carried out in accordance with the protocols approved by the Capital Medical University Animal Care and Use Committee (Permission No: 2012-X-108).

\section{TsPmy DNA Vaccine}

The DNA encoding full-length TsPmy (GenBank ID: EF429310) was cloned into the eukaryotic expression vector $\mathrm{pVAX} 1$, and the recombinant $\mathrm{pVAX} 1-T s$ Pmy plasmid DNA was transformed into an attenuated S. typhimurium (SL7207) which was aroA mutant strain with 2337-2365 derivative hisG46 DEL407 (aroA::Tn10 $\{$ Tc-s\}) by electroporation $(2.5 \mathrm{kV}, 25 \mu \mathrm{F}$, and $200 \Omega)$ as an oral
DNA vaccine (SL7207/pVAX1-TsPmy), the transformants were selected on plates with $50 \mu \mathrm{g} / \mathrm{ml}$ kanamycin and identified by PCR amplification and restriction enzyme digestion. The PCR products were then confirmed by DNA sequencing as previous described (Wang et al., 2016).

\section{Recombinant TsPmy Protein (rTsPmy)}

DNA encoding Ts Pmy without signal peptide was cloned into the expression vector pET-28a (+). The recombinant TsPmy protein (rTsPmy) was expressed and identified in an Escherichia coli (BL21) expression system in our laboratory. The rTsPmy with a His-tag at the $\mathrm{C}$ terminus was expressed in E. coli under $1 \mathrm{mM}$ IPTG induction and purified with Ni-affinity chromatography (Qiagen, United States) as previously described (Yang et al., 2008).

\section{Parasites}

Trichinella spiralis (ISS 533) parasites used in this study were originally isolated from an infected pig in Heilongjiang, China and maintained by serial passage in female ICR mice in our laboratory (Cui and Wang, 2001). The adult worms from the small intestines of infected mice were isolated 5 days postinfection (dpi). T. spiralis muscle larvae (ML) from infected mice were recovered at $42 \mathrm{dpi}$ via a previously described pepsinhydrochloric acid digestion method (Gamble et al., 2000).

\section{Immunization Regimens and Sample Collection}

$\mathrm{BALB} / \mathrm{c}$ mice were randomly divided into six groups and each group was composed of 40 animals. For the heterologous primeboost group (DNA+Protein), each mouse was inoculated orally with $1 \times 10^{8}$ attenuated S. typhimurium SL7207 containing pVAX1-TsPmy (SL7207/pVAX1-TsPmy) as previously described (Wang et al., 2016) and then boosted intramuscularly twice with $25 \mu \mathrm{g}$ rTsPmy emulsified with an equal volume of the water-in-oil adjuvant ISA 50V2 (SEPPIC, France) at 2-weeks interval. For DNA or recombinant protein vaccination groups, mice were immunized either orally with $1 \times 10^{8}$ bacteria of SL7207/pVAX1-TsPmy (DNA) or intramuscularly with $25 \mu \mathrm{g}$ of rTsPmy formulated with ISA 50V2 (Protein) for three times at 2-weeks interval. The other three control groups were given with either the same number bacteria with empty vector of SL7207/pVAX1 orally (Vector), or PBS alone (emulsified with ISA 50V) intramuscularly for three times, or first oral vector followed with two PBS intramuscularly to mimic heterologous prime-boost regimen (Vector+PBS) as shown in Table $\mathbf{1}$.

Before immunization and 1 week after each immunization, five mice from each group were sacrificed; the lavage fluid of intestines, serum, mesenteric lymph nodes (MLNs), and spleen were collected from each mouse to examine the levels of mucosal, humoral and cellular immune responses, as previously described (Wang et al., 2016). All animals were daily monitored for general appearance, abnormal locomotion, eye abnormality, labored breathing, head tilt, hyperactivity, lethargy, paresis, lameness, paralysis, ruffled fur, and tremors. Mice would be euthanized immediately by $\mathrm{CO}_{2}$ inhalation if there was any severe sign 
TABLE 1 | Immunization groups (immunization route).

\begin{tabular}{|c|c|c|c|}
\hline Groups & Prime & 1st boost & 2nd boost \\
\hline DNA+Protein & SL7207/pVAX1-TsPmy(orally) & rTsPmy(intramuscularly) & rTsPmy(intramuscularly) \\
\hline DNA & SL7207/pVAX1-TsPmy(orally) & SL7207/pVAX1-TsPmy(orally) & SL7207/pVAX1-TsPmy(orally) \\
\hline Protein & rTsPmy(intramuscularly) & rTsPmy(intramuscularly) & rTsPmy(intramuscularly) \\
\hline Vector+PBS & SL7207/pVAX1(orally) & PBS(intramuscularly) & PBS(intramuscularly) \\
\hline Vector & SL7207/pVAX1(orally) & SL7207/pVAX1 (orally) & SL7207/pVAX1(orally) \\
\hline PBS & PBS(intramuscularly) & PBS(intramuscularly) & PBS(intramuscularly) \\
\hline
\end{tabular}

of abnormality including bleeding diarrhea, leg injuries or in moribund condition.

\section{Humoral Antibody Responses in Systemic and Mucosal Immunity}

The levels of TsPmy-specific total IgG, IgG1, and IgG2a antibodies in the sera of the immunized mice were detected via a modified ELISA using rTsPmy coated on plates as described previously (Yang et al., 2010). Briefly, microtiter plates were coated with rTsPmy $(1 \mu \mathrm{g} / \mathrm{ml})$ at $4^{\circ} \mathrm{C}$ overnight. Then, $100 \mu \mathrm{l}$ of sera samples diluted in PBS at 1:1000 was added to each well. HRP-conjugated goat-anti-mouse $\operatorname{IgG}$, IgG1, or IgG2a antibodies were added as secondary antibodies. 3,3',5,5' tetramethylbenzidine was used as a substrate and the reactions were stopped with $50 \mu \mathrm{l}$ per-well of $2 \mathrm{M} \mathrm{H}_{2} \mathrm{SO}_{4}$. Absorbance at $450 \mathrm{~nm}$ was measured with a microplate reader. All samples were run in triplicate.

To evaluate the secreted IgA (sIgA) level, the $10 \mathrm{~cm}$ interior small intestine from each sacrificed mouse was washed twice with $2 \mathrm{ml}$ of cold PBS. After centrifugation at $800 \times g$ for $10 \mathrm{~min}$, the supernatants were harvested. Intestinal total $\operatorname{sig} \mathrm{A}$ was quantified with sandwich-type ELISA using rat anti-mouse IgA antibody as the capture antibody. The specific TsPmy-specific sIgA in intestinal lavage fluid of each mouse was measured by standard ELISA using rTsPmy as antigen coated on plates, respectively, as described previously (Yang et al., 2010; Wang et al., 2016).

\section{Cellular Cytokine Assay}

To examine the specific cellular immune responses against rTsPmy, the cytokine profiles in splenocytes and MLN cells from immunized mice were analyzed upon re-stimulation with the rTsPmy antigen in vitro using a modified ELISPOT assay (BD Bioscience, United States). In brief, spleen and the MLN cells were isolated aseptically from mice 7 days after each immunization and the single lymphocyte suspensions were prepared in RPMI-1640. $1 \times 10^{6}$ lymphocytes were added to each well of plates pre-coated with the capture antibody (antimouse IFN- $\gamma$, IL-2, IL-4, IL-6, and IL-10) at 1: 200 dilutions in PBS and incubated at $4^{\circ} \mathrm{C}$ overnight. After stimulation with $1 \mu \mathrm{g} / \mathrm{ml}$ of $\mathrm{r} T s$ Pmy for $48 \mathrm{~h}$, the biotinylated secondary antibodies were added for $2 \mathrm{~h}$, then incubated with streptavidin-HRP for $1 \mathrm{~h}$ and developed with $100 \mu \mathrm{L}$ of 3-amino-9-ethylcarbazole substrate solution (BD Biosciences, United States) for $30 \mathrm{~s}-5 \mathrm{~min}$. The spots secreted with IFN- $\gamma$, IL-2, IL-4, IL-6, and IL-10 were counted as spot forming units (SFUs) with a CTL ELISPOT reader and analyzed using ImmunoSpot image analyzer software v4.0.

\section{Challenge Experiment}

Two weeks after the final boost, the remaining 20 mice in each group were orally challenged with 500 T. spiralis ML per mouse. Ten mice from each group were euthanized 5 days after challenge and the adult worms were collected and counted. The left 10 mice were euthanized 42 days after challenge infection and the muscle larva were collected and counted. The adult worm and muscle larvae reduction in immunized mouse groups was calculated compared with those from the PBS control mice.

\section{Statistical Analysis}

One-way ANOVA was used for data comparison among different groups with SPSS version 17.0 software and expressed as the means \pm standard deviation (SD), $p<0.05$ was regarded as statistically significant.

\section{RESULTS}

\section{Systemic Humoral Response Elicited by Different Regimen}

Mouse sera collected 1 week after each immunization were used to determine the antibody levels of anti-TsPmy IgG and its subtype (IgG1 and IgG2a). The anti-TsPmy specific IgG was detected in sera of mice immunized with DNA+Protein, DNA, or Protein alone after first immunization compare to the three empty control groups. The anti-Ts Pmy IgG reached the highest titers after three immunizations. Specifically, mice immunized with protein prime-boost (Protein) produced significant high titers of anti-TsPmy IgG after the first immunization and remained the plateau after two boosts. The anti-TsPmy IgG level in mice of DNA+Protein prime-boost group was significantly increased after first boost with rTs Pmy and reached to even higher titer than mice in Protein prime-boost group after three immunizations. The mice immunized with DNA primeboost produced lower anti-TsPmy IgG titer than other two vaccine groups after three immunizations. However, none of the mice in control groups received Vector+PBS, Vector or PBS alone showed any detectable TsPmy specific IgG response (Figure 1A). Similarly, after three immunizations, mice immunized with DNA+Protein produced highest antiTsPmy IgG1 and IgG2a compared to DNA or Protein 

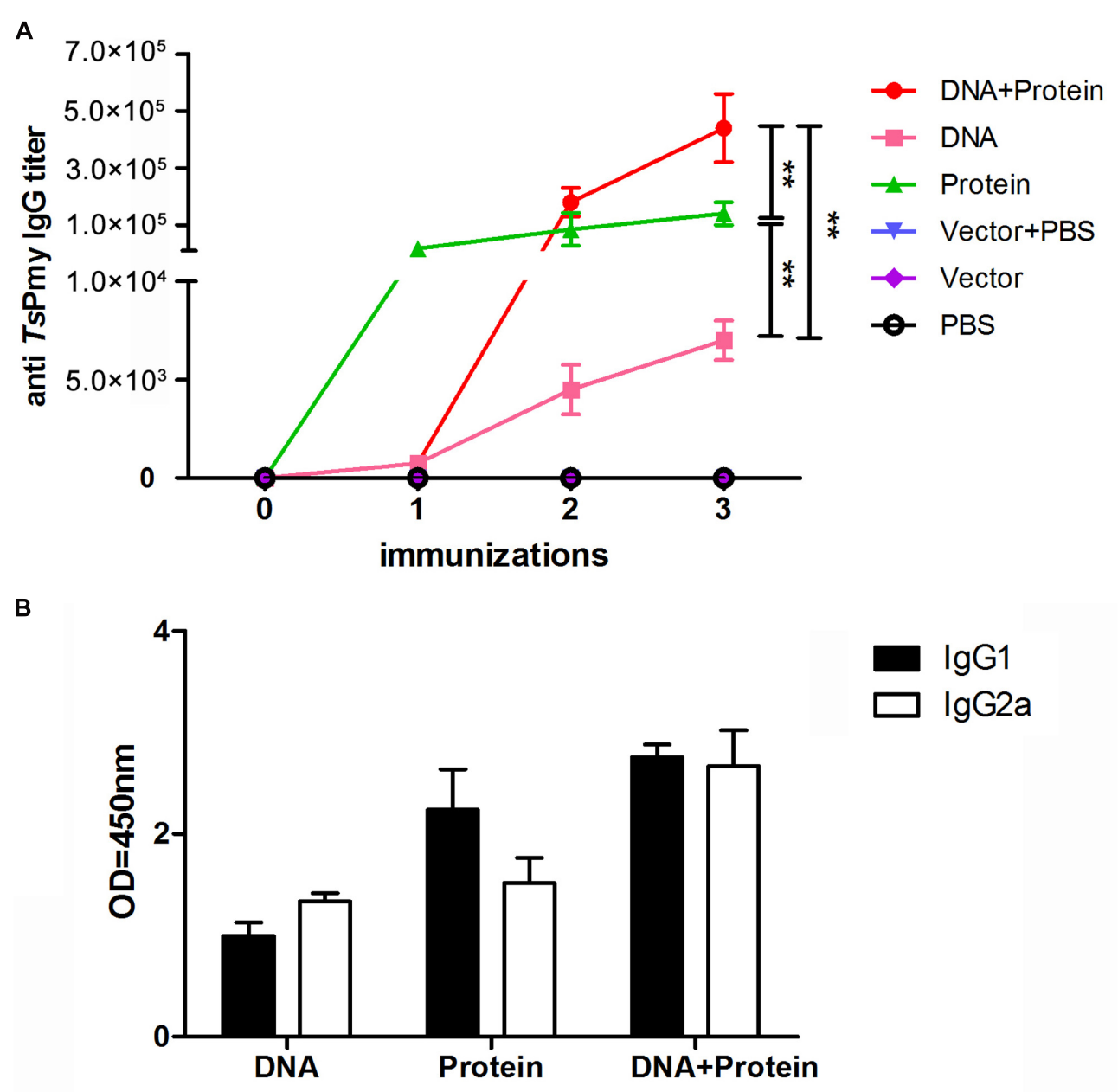

FIGURE 1 | Analysis of sera antibody responses in mice immunized with TsPmy in different regimens. (A) Specific anti-TsPmy lgG levels in the sera of immunized mice at different immunization time points for five individual mice. (B) The levels of the subclass IgG1 and IgG2a when sera were diluted at 1:200. The OD values shown for each group are the mean \pm standard deviation (SD) of the antibody levels. ${ }^{* *} p<0.01$ between two groups.

homologous prime-boost groups and the IgG1 and IgG2a level was proximately equal, indicating balanced Th1/Th2 immune responses were induced in heterologous prime-boost immunization. Mice immunized with Protein prime-boost produced higher IgG1 than IgG2a, indicating predominant Th2 responses. Mice immunized with DNA alone produced lowest anti-TsPmy IgG1 and IgG2a compared to other two vaccine groups, with IgG2a predominant (Figure 1B).

\section{Intestinal Mucosal sigA Response}

The intestinal total sIgA were measured by a sandwich ELISA and anti-TsPmy specific sIgA were evaluated using an rTsPmy coated plate in intestinal mucosal washings. Intestinal total sIgA level was significantly increased in the intestinal mucosa of mice immunized with DNA+Protein, DNA, and Vector alone compared to other groups after second immunization. Mice immunized with DNA+Protein (only one immunization of oral DNA) produced lower total sIgA compared to mice immunized with three immunizations of DNA or Vector alone, indicating that the total sIgA was induced mostly by attenuated Salmonella bacteria (Figure 2A). The anti-TsPmy specific sIgA was detected only in mice immunized with DNA and DNA+Protein. Mice immunized with once oral DNA followed by two boosts of protein (DNA+Protein) elicited the similar level of antigenspecific sIgA as mice immunized with oral DNA for three times (DNA) without significant difference. Mice immunized with protein (intramuscular) or empty vector did not induce any anti-TsPmy sIgA response (Figure 2B).

\section{Dynamic Cytokine Profiles}

The cytokine responses including IFN- $\gamma$, IL-2, IL-4, IL-5, IL-6, and IL-10 in splenocytes (Figure 3) and MLN cells (Figure 4) were measured by ELISPOT 1 week after each immunization. All of the cytokines were significantly increased after the first immunization and reached the highest after three immunizations in mice immunized with DNA+Protein, DNA, or Protein alone in both splenocytes and MLN cells upon re-stimulation of rTsPmy. In the systematic splenocyte responses, mice immunized 


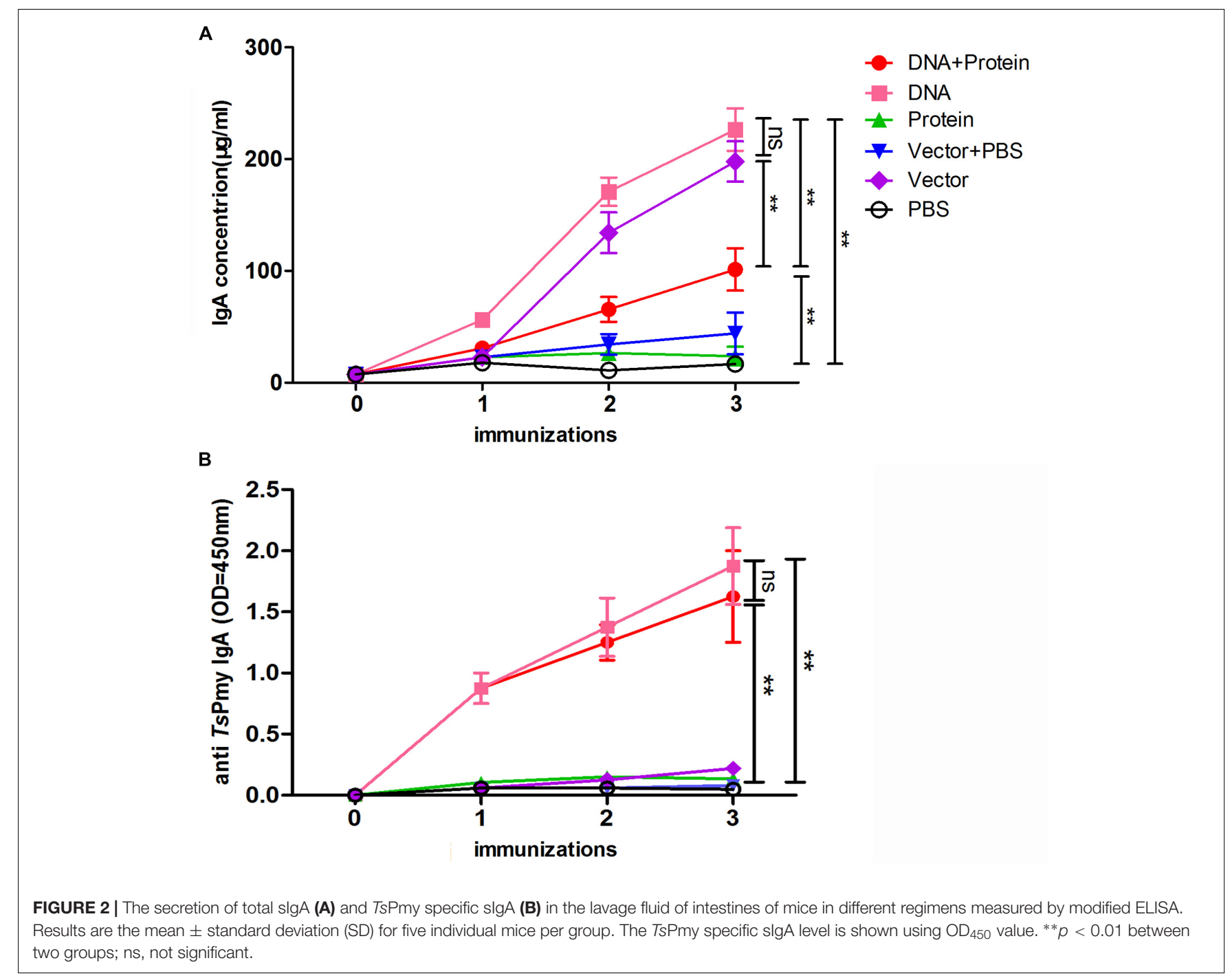

with DNA+Protein produced significant higher Th1 cytokines including IFN- $\gamma$ and IL- 2 than mice immunized with DNA or Protein alone, similar levels of Th2 cytokines (IL-4, IL-5, IL-6, and IL-10) to the mice immunized with recombinant protein (Protein). Even though mice immunized with DNA primeboost produced significant level of Th1 cytokines (IFN- $\gamma$ and IL-2), the level of Th2 cytokines (IL-4, IL-5, IL-6, and IL-10) were much lower than groups immunized with DNA+Protein or Protein alone (Figure 3). The similar pattern of cytokine profile was observed in the local MLN cell responses to the restimulation of $\mathrm{rTs}$ Pmy, with high Th1 cytokine responses (IFN- $\gamma$ and IL-2) in mice immunized with DNA prime-boost, high Th2 cytokine (IL-4, IL-5, IL-6, and IL-10) responses in mice immunized with Protein prime-boost, and with highest Th1/Th2 cytokine responses for mice immunized with DNA+Protein prime-boost (Figure 4). There was no significant cytokine response in both splenocytes and MLN cells from empty control mice. These results suggest that mice immunized with TsPmy using heterologous prime-boost immunization regimen induced highest Th1 and Th2 cytokine responses in both systemic lymphocytes (spleen) and local lymphocytes around the intestine (MLNs).

\section{Protective Immunity}

Two weeks after final immunization with TsPmy in different regimens, six groups of mice were challenged orally with 500 ML per mouse. The worm burden results reveal that mice immunized with DNA+Protein prime-boost, DNA alone and Protein alone prime-boost produced 41.8, 44.8, and $10.1 \%$, respectively, adult worm reduction compared with mice received PBS control (Figure 5A). Mice immunized with DNA+Protein and DNA alone prime-boost induced significant higher adult worm reduction than mice immunized with Protein alone prime-boost. Muscle larvae collection 42 days after challenge demonstrated that mice immunized with DNA+Protein primeboost, DNA and Protein alone prime-boost produced 55.4, 46.6 , or $36.6 \%$ muscle larvae reduction, respectively, compared to mice received PBS control $(p<0.01)$ (Figure 5B). The number of adult worms and ML collected from each group of mice was shown in Supplementary Table 1. The statistical 


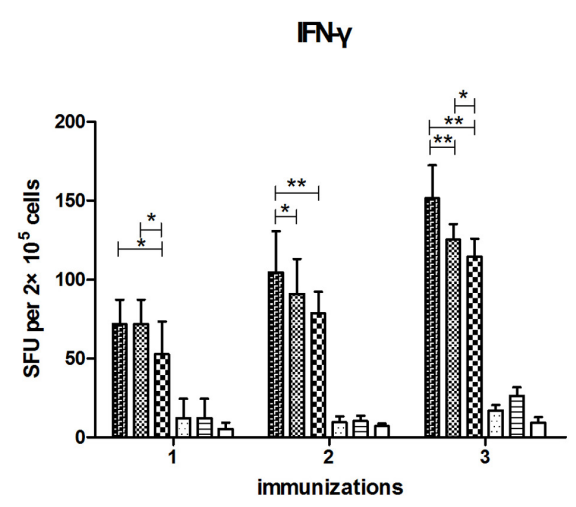

IL-4

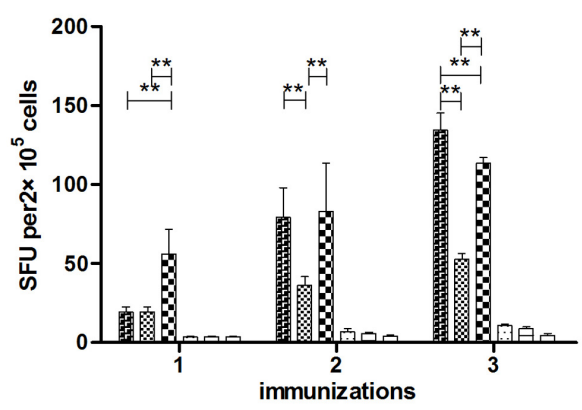

IL-6

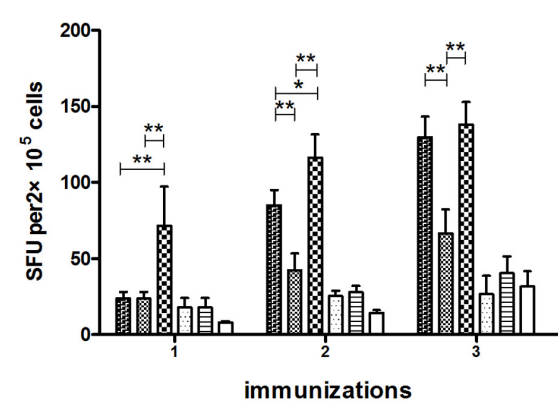

IL-2

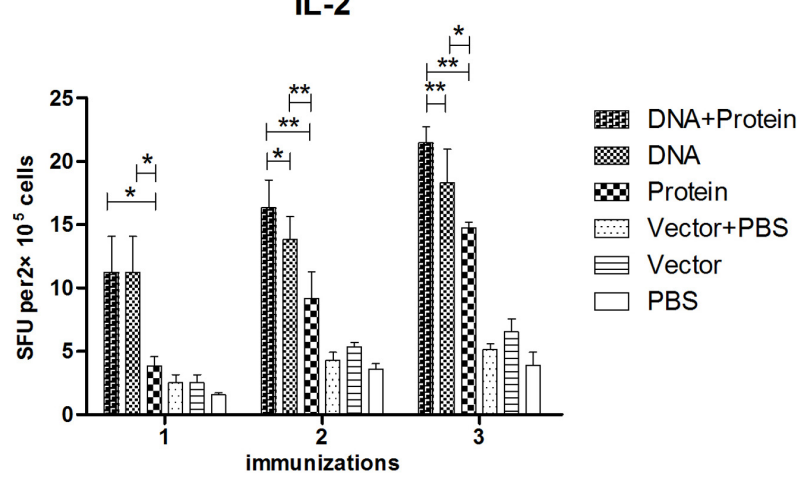

IL-5

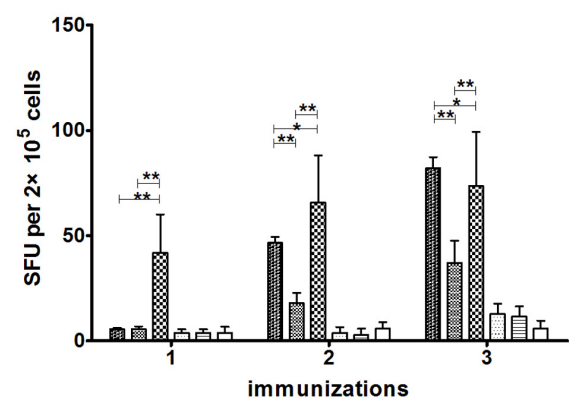

IL-10

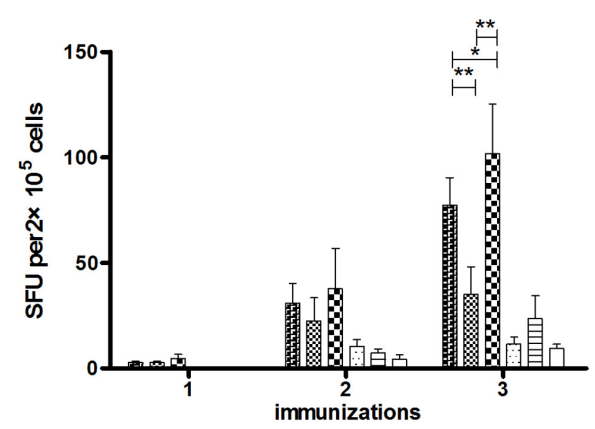

FIGURE 3 | Dynamic cytokine profile secreted by splenocytes upon rTsPmy re-stimulation. Splenocytes secreting Th1 cytokines (IFN- $\gamma$ and IL-2), Th2 cytokines (IL-4, IL-5, IL-6, and IL-10) upon re-stimulated with $1 \mu \mathrm{g} / \mathrm{ml}$ of $r T s P m y$ for $48 \mathrm{~h}$ were detected by ELISPOT assays. The values shown for each group are the mean \pm standard deviation (SD) of cytokine levels from five individual mice. ${ }^{*} p<0.05 ;{ }^{* *} p<0.01$ between two groups.

analysis shows that mice immunized with TsPmy in DNA/protein heterologous prime-boost regimen produced significant higher larvae reduction than mice in groups of DNA prime-boost $(p<0.05)$ and protein prime-boost $(p<0.05)$, mice immunized with Ts Pmy in DNA prime-boost regimen produced higher larvae reduction than mice in protein prime-boost $(p<0.05)$. These adult and muscle larvae reduction results indicate that TsPmy immunization in DNA/protein heterologous prime-boost regimen induced significantly higher protective immunity than the DNA or protein homologous prime-boost regimens against
T. spiralis infection in $\mathrm{BALB} / \mathrm{c}$ mice, especially at the larvae reduction level.

\section{DISCUSSION}

In general, DNA vaccine and recombinant protein vaccine stimulates different antigen-specific immune response using different mechanisms, the former induce strong Th1 cellular immune responses and also prime antigen-specific memory B 


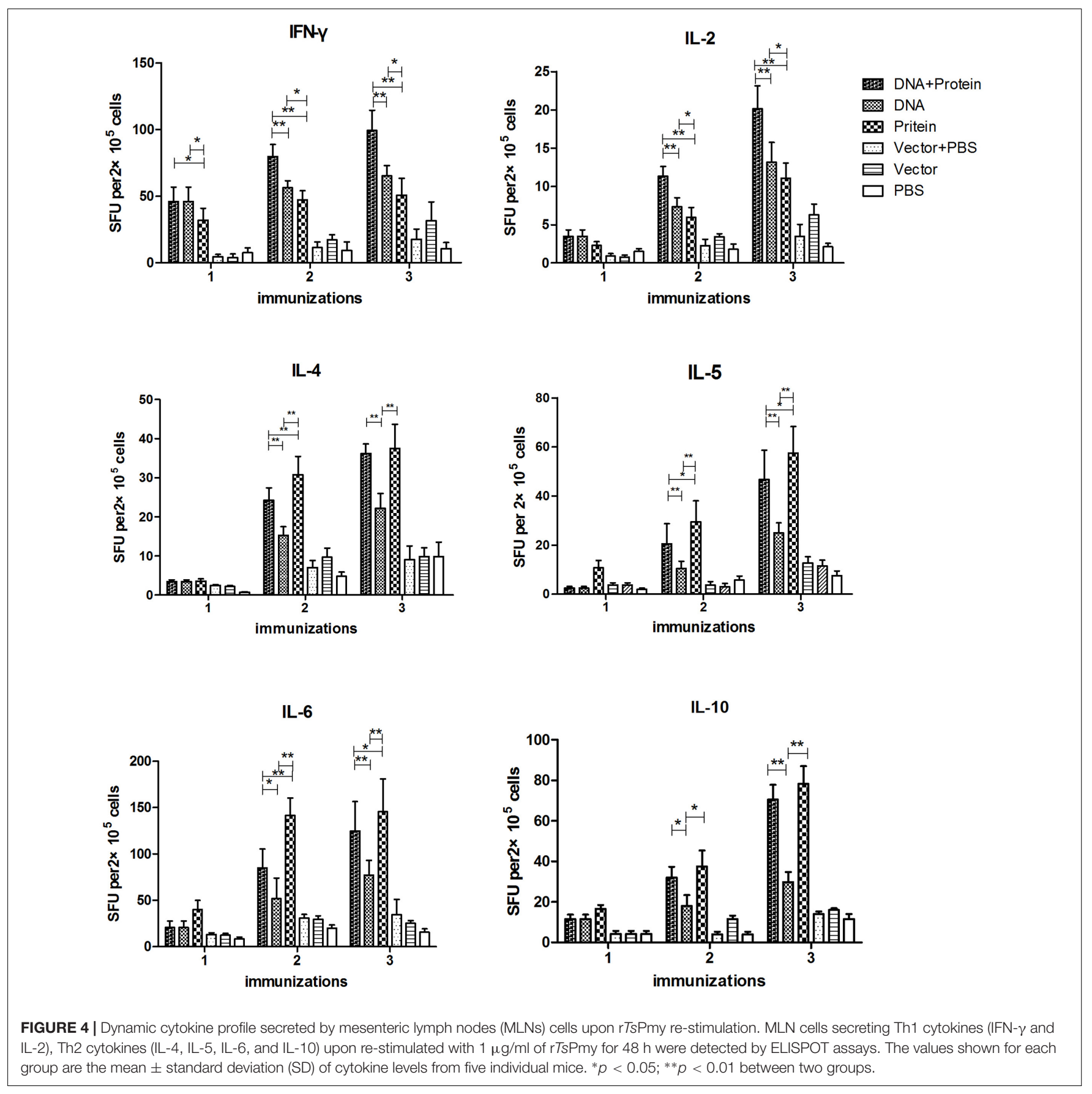

cells, and the latter induce predominant Th2 antibody responses (Jackson et al., 2014; Kardani et al., 2016). This different immunological mechanisms lead to the heterogeneous DNAprime and protein-boost immunization regimen in order to enhance both cellular and humoral immune responses. DNA vaccine is used to prime immune responses including antigenspecific memory B cells. A protein vaccine is followed as boosting immunization to directly stimulate memory B cells to differentiate into antibody-producing cells (Alekseeva et al., 2009; Ranasinghe and Ramshaw, 2009). This heterologous prime-boost regimen has been proven to be more effective than homologous prime-boost approach (Nascimento and Leite, 2012; Rafferty et al., 2014). This type of heterologous prime-boost may elicit unique cellular and humoral immune responses as well as mucosal immune response to achieve improved and suitable immune responses to defense different pathogens including viral, bacterial, and parasitic infections (Butts et al., 2016; Vemula et al., 2016).

In our previous studies, immunization with rTsPmy protein, immunogenic epitope peptides (Wei et al., 2011; Gu et al., 2013), or TsPmy DNA vaccine delivered by attenuated bacteria vector (Wang et al., 2016) induced certain extent of protective immune 


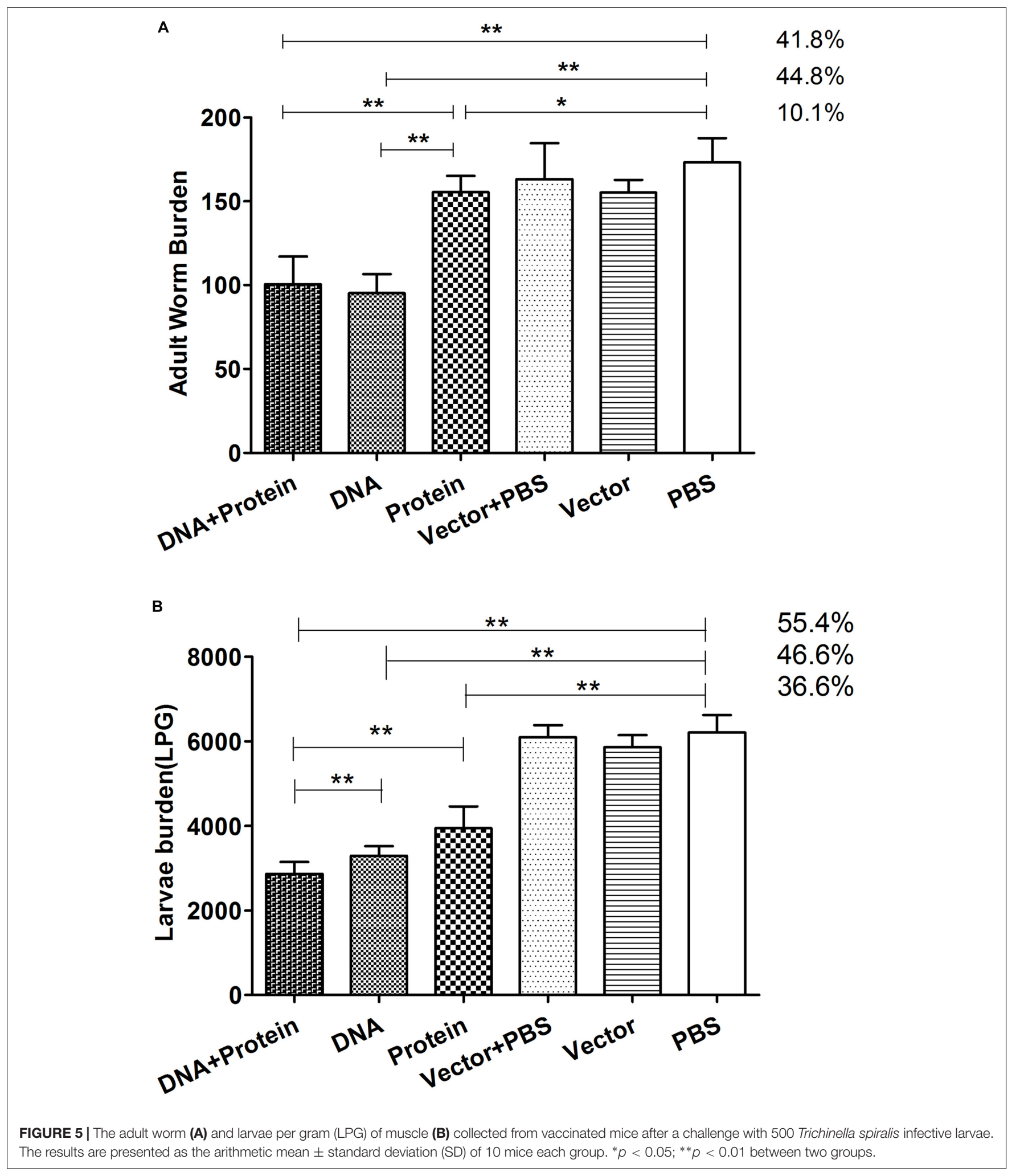

responses against Trichinella infection. The previous vaccine efficacy comparison among available TsPmy-based T. spiralis vaccines was shown in Supplementary Table 2. However, the protection efficacy induced by these homologous prime-boost immunizations is insufficient (33.44-46.6\% protection for ML). In this study, we report that a vaccination with heterologous prime-boost strategy comprised of oral prime inoculation with TsPmy DNA vaccine delivered by attenuated S. typhimurium 
(SL7207) and two intramuscular boosts with rTsPmy protein, strongly elicited both cell medicated immune responses and humoral immune responses. The robust balanced Th1/Th2 immune responses upon the TsPmy heterologous prime-boost immunization produced the optimal protective efficacy with $41.8 \%$ adult worm reduction and $55.4 \%$ larvae reduction in a mouse model compared to homologous regimens vaccinated with TsPmy DNA (44.8\%/46.6\% reduction for adult worm/ML) or Protein $(10.1 \%$ and $36.6 \%)$ alone. In particular, TsPmy heterologous prime-boost immunization induced significant better reduction of muscle larvae, which cause major disease manifestation of trichinellosis in humans (Gottstein et al., 2009).

Mucosal immunity acts as the first barrier of defense against intestinal pathogens such as $T$. spiralis. It has been demonstrated that mucosal IgA response was able to impede the establishment of Trichinella adult worms in the mouse intestine (Ding et al., 2016). Previous study has demonstrated that oral immunization with TsPmy/S. typhimurium DNA vaccine induced TsPmyspecific sIgA secretion in intestinal mucosa possibly through inducing the expression of CCR9/CCR10, the homing receptors, on antibody secreting B cells and B cell translocation to local intestinal mucosa (Wang et al., 2016). In this study, one oral immunization with S. typhimurium-delivered TsPmy DNA in the heterologous DNA/prime and protein/boost regimen induced the similar level of antigen-specific sIgA (Figure 2B) in gut mucosa as the three immunizations of homologous DNA primeboost regimen, indicating one oral immunization of TsPmy is potent to induce mucosal $\operatorname{sgA}$ and the following boosted recombinant protein may stimulate the specific $\mathrm{B}$ memory cells in mucosa to produce sIgA, which also reflects the similar adult worm reduction in the gut between the groups of TsPmy heterologous DNA-protein and homologous DNA immunizations.

Indeed, oral immunization with S. typhimurium-delivered TsPmy DNA induced strong mucosa sIgA that may contribute to the protection against adult worm parasitism in the gut; however, mucosal sIgA alone is insufficient to provide solid protection against intestinal pathogen infections (Azegami et al., 2014; Zaph et al., 2014), especially has no effect on the newborn larvae that have already penetrated through mucosa and migrated to muscle to form muscle larvae. A systemic immune response, including humoral antibody and cellular response, is needed to defend invaded larvae (Yang et al., 2016). It is well-known that protein antigens are able to strongly boost systemic immune responses and a combination of DNA prime and protein-boost significantly augmented and elongated humoral and cellular responses to HIV Env (Jalah et al., 2014). In this study, significantly greater systemic humoral and cellular immune responses were observed in the heterologous DNA-prime and protein-boost immunization with Trichinella leading vaccine antigen TsPmy. In addition to the strong intestinal mucosal sIgA response, the anti-TsPmy specific IgG antibody was significantly increased after being boosted with rTsPmy protein and reached to peak value after the second boost with rTsPmy, which was even greater than protein prime-boost vaccination group. Cytokine profile of systemic lymphocytes (spleen) and intestinal local lymphocytes (MLN) upon re-stimulation of rTsPmy also showed that Th1 cytokines (IFN- $\gamma$, IL-2) was induced in DNA immunization, and significantly boosted by following intramuscular immunizations of $\mathrm{r} T s$ Pmy to the level which is even higher than that boosted by DNA prime-boost vaccination. The heterologous DNA-prime and protein-boost immunization also boosted strong Th2 cytokines (IL-4, IL-5, IL-6, and IL-10) to the similar level as group in protein prime-boost regimen. Both humoral and cellular immune responses play important roles against pathogenic T. spiralis infections (Lee and Ko, 2006). The heterologous prime-boost regimen may contribute to the better protection against Trichinella infection than DNA or protein homologous prime-boost regimens, especially with significant better protection against the formation of muscle larvae.

\section{CONCLUSION}

We demonstrate here that a heterologous immunization regimen with $T s$ Pmy DNA-prime orally delivered by attenuated S. typhimurium and protein-boost effectively induced mucosal sIgA response and an enhanced and balanced Th1/Th2 systemic immune responses that resulted in improved protection against T. spiralis infection, with $55.4 \%$ muscle larvae reduction which is significant higher than that induced by the homologous DNA or protein prime-boost regimen. Such an immunization strategy, plus combination with other protective antigen, would be a better approach to enhance protective immunity and could be used to better control trichinellosis in human and domestic animals.

\section{AUTHOR CONTRIBUTIONS}

$\mathrm{XZ}$ and LW conceived and designed the experiments. LW, XS, and $\mathrm{JH}$ performed the experiments. $\mathrm{XZ}, \mathrm{LW}$, and $\mathrm{BZ}$ analyzed the data. LW, XZ, and BZ wrote the paper. All authors reviewed the manuscript.

\section{FUNDING}

This study was supported by grants from the National Natural Science Foundation of China (No. 81371837, No. 81672042) and Beijing Natural Science Foundation (No. 7162017).

\section{ACKNOWLEDGMENT}

We thank Jing Yang, Yuan Gu, Xiaohuan Wang, Kuo Bi, and Zixia Wang for their technical assistance.

\section{SUPPLEMENTARY MATERIAL}

The Supplementary Material for this article can be found online at: http://journal.frontiersin.org/article/10.3389/fmicb.2017. 01394/full\#supplementary-material 


\section{REFERENCES}

Alekseeva, E., Sominskaya, I., Skrastina, D., Egorova, I., Starodubova, E., and Kushners, E. (2009). Enhancement of the expression of HCV core gene does not enhance core-specific immune response in DNA immunization: advantages of the heterologous DNA prime, protein boost immunization regimen. Genet. Vaccines Ther. 7:7. doi: 10.1186/1479-0556-7-7

Azegami, T., Yuki, Y., and Kiyono, H. (2014). Challenges in mucosal vaccines for the control of infectious diseases. Int. Immunol. 26, 517-528. doi: 10.1093/ intimm/dxu063

Butts, C. L., Ricks, I. P., and August, A. (2016). Prime-boost strategies to embrace diversity and inclusion in immunology. Nat. Rev. Immunol. 16, 715-716. doi: 10.1038/nri.2016.122

Cabrera-Mora, M., Fonseca, J. A., Singh, B., Zhao, C., Makarova, N., and Dmitriev, I. (2016). A recombinant chimeric Ad5/3 vector expressing a multistage plasmodium antigen induces protective immunity in mice using heterologous prime-boost immunization regimens. J. Immunol. 197, 2748-2761. doi: 10.4049/jimmunol.1501926

Cui, J., and Wang, Z. Q. (2001). Outbreaks of human trichinellosis caused by consumption of dog meat in China. Parasite 8, S74-S77. doi: 10.1051/parasite/ 200108s2074

Cui, J., Wang, Z. Q., and Xu, B. L. (2011). The epidemiology of human trichinellosis in China during 2004-2009. Acta Trop. 118, 1-5. doi: 10.1016/j.actatropica. 2011.02.005

Dai, Y., Zhao, S., Tang, J., Xing, Y., Qu, G., and Dai, J. (2017). Evaluation of protective efficacy induced by different heterologous prime-boost strategies encoding triosephosphate isomerase against Schistosoma japonicum in mice. Parasit. Vectors 10:111. doi: 10.1186/s13071-017-2036-5

Ding, J., Bai, X., Wang, X. L., Wang, Y. F., Shi, H. N., and Rosenthal, B. (2016). Developmental profile of select immune cells in mice infected with Trichinella spiralis during the intestinal phase. Vet. Parasitol. 231, 77-82. doi: 10.1016/j. vetpar.2016.07.019

Dupouy-Camet, J. (2000). Trichinellosis: a worldwide zoonosis. Vet. Parasitol. 93, 191-200.

Gamble, H. R., Bessonov, A. S., Cuperlovic, K., Gajadhar, A. A., van Knapen, F., and Noeckler, K. (2000). International commission on trichinellosis: recommendations on methods for the control of Trichinella in domestic and wild animals intended for human consumption. Vet. Parasitol. 93, 393-408.

Gottstein, B., Pozio, E., and Nockler, K. (2009). Epidemiology, diagnosis, treatment, and control of trichinellosis. Clin. Microbiol. Rev. 22, 127-145. doi: 10.1128/ CMR.00026-08

Gu, Y., Li, J., Zhu, X., Yang, J., Li, Q., and Liu, Z. (2008). Trichinella spiralis: characterization of phage-displayed specific epitopes and their protective immunity in BALB/c mice. Exp. Parasitol. 118, 66-74. doi: 10.1016/j.exppara. 2007.06.014

Gu, Y., Wei, J., Yang, J., Huang, J., Yang, X., and Zhu, X. (2013). Protective immunity against Trichinella spiralis infection induced by a multi-epitope vaccine in a murine model. PLOS ONE 8:e77238. doi: 10.1371/journal.pone. 0077238

Han, Y., Zhou, A., Lu, G., Zhao, G., Wang, L., and Guo, J. (2017). Protection via a ROM4 DNA vaccine and peptide against Toxoplasma gondii in BALB/c mice. BMC Infect. Dis. 17:59. doi: 10.1186/s12879-016-2104-z

Jackson, R. J., Boyle, D. B., and Ranasinghe, C. (2014). Progresses in DNA-based heterologous prime-boost immunization strategies. Methods Mol. Biol. 1143, 61-90. doi: 10.1007/978-1-4939-0410-5_5

Jalah, R., Kulkarni, V., Patel, V., Rosati, M., Alicea, C., and Bear, J. (2014). DNA and protein co-immunization improves the magnitude and longevity of humoral immune responses in macaques. PLoS ONE 9:e91550. doi: 10.1371/journal. pone.0091550

Kardani, K., Bolhassani, A., and Shahbazi, S. (2016). Prime-boost vaccine strategy against viral infections: mechanisms and benefits. Vaccine 34, 413-423. doi: 10.1016/j.vaccine.2015.11.062
Lee, K. M., and Ko, R. C. (2006). Cell-mediated response at the muscle phase of Trichinella pseudospiralis and Trichinella spiralis infections. Parasitol. Res. 99, 70-77. doi: 10.1007/s00436-005-0101-z

Nascimento, I. P., and Leite, L. C. (2012). Recombinant vaccines and the development of new vaccine strategies. Braz. J. Med. Biol. Res. 45, $1102-1111$.

Picherot, M., Oswald, I. P., Cote, M., Noeckler, K., Le Guerhier, F., and Boireau, P. (2007). Swine infection with Trichinella spiralis: comparative analysis of the mucosal intestinal and systemic immune responses. Vet. Parasitol. 143, 122-130. doi: 10.1016/j.vetpar.2006.08.003

Rafferty, H., Sibeko, S., and Rowland-Jones, S. (2014). How can we design better vaccines to prevent HIV infection in women? Front. Microbiol. 5:572. doi: 10.3389/fmicb.2014.00572

Ranasinghe, C., and Ramshaw, I. A. (2009). Genetic heterologous prime-boost vaccination strategies for improved systemic and mucosal immunity. Expert Rev. Vaccines 8, 1171-1181. doi: 10.1586/erv.09.86

Shahbazi, M., Zahedifard, F., Saljoughian, N., Doroud, D., Jamshidi, S., and Mahdavi, N. (2015). Immunological comparison of DNA vaccination using two delivery systems against canine leishmaniasis. Vet. Parasitol. 212, 130-139. doi: 10.1016/j.vetpar.2015.07.005

Vemula, M. H., Ganji, R., Sivangala, R., Jakkala, K., Gaddam, S., and Penmetsa, S. (2016). Mycobacterium tuberculosis zinc metalloprotease-1 elicits tuberculosisspecific humoral immune response independent of mycobacterial load in pulmonary and extra-pulmonary tuberculosis patients. Front. Microbiol. 7:418. doi: $10.3389 /$ fmicb.2016.00418

Wang, L., Wang, X., Bi, K., Sun, X., Yang, J., and Gu, Y. (2016). Oral vaccination with attenuated Salmonella typhimurium-delivered TsPmy DNA vaccine elicits protective immunity against Trichinella spiralis in BALB/c mice. PLoS Negl. Trop. Dis. 10:e4952. doi: 10.1371/journal.pntd.0004952

Wang, S., Zhu, X., Yang, Y., Yang, J., Gu, Y., and Wei, J. (2009). Molecular cloning and characterization of heat shock protein 70 from Trichinella spiralis. Acta Trop. 110, 46-51. doi: 10.1016/j.actatropica.2009.01.003

Wang, Z. Q., Cui, J., and Xu, B. L. (2006). The epidemiology of human trichinellosis in China during 2000-2003. Acta Trop. 97, 247-251. doi: 10.1016/j.actatropica. 2005.03.012

Wei, J., Gu, Y., Yang, J., Yang, Y., Wang, S., and Cui, S. (2011). Identification and characterization of protective epitope of Trichinella spiralis paramyosin. Vaccine 29, 3162-3168. doi: 10.1016/j.vaccine.2011.02.072

Yang, J., Gu, Y., Yang, Y., Wei, J., Wang, S., and Cui, S. (2010). Trichinella spiralis: immune response and protective immunity elicited by recombinant paramyosin formulated with different adjuvants. Exp. Parasitol. 124, 403-408. doi: 10.1016/j.exppara.2009.12.010

Yang, J., Yang, Y., Gu, Y., Li, Q., Wei, J., and Wang, S. (2008). Identification and characterization of a full-length cDNA encoding paramyosin of Trichinella spiralis. Biochem. Biophys. Res. Commun. 365, 528-533. doi: 10.1016/j.bbrc. 2007.11.012

Yang, J., Zhu, W., Huang, J., Wang, X., Sun, X., and Zhan, B. (2016). Partially protective immunity induced by the 14-3-3 protein from Trichinella spiralis. Vet. Parasitol. 231, 63-68. doi: 10.1016/j.vetpar.2016.06.028

Zaph, C., Cooper, P. J., and Harris, N. L. (2014). Mucosal immune responses following intestinal nematode infection. Parasite Immunol. 36, 439-452. doi: $10.1111 /$ pim. 12090

Conflict of Interest Statement: The authors declare that the research was conducted in the absence of any commercial or financial relationships that could be construed as a potential conflict of interest.

Copyright (c) 2017 Wang, Sun, Huang, Zhan and Zhu. This is an open-access article distributed under the terms of the Creative Commons Attribution License (CC BY). The use, distribution or reproduction in other forums is permitted, provided the original author(s) or licensor are credited and that the original publication in this journal is cited, in accordance with accepted academic practice. No use, distribution or reproduction is permitted which does not comply with these terms. 